\title{
A IMAGINAÇÃO COMO ATIVIDADE CRIADORA
}

\author{
Luis Henrique Zago ${ }^{1}$, Allan Alberto Ferreira ${ }^{2}$, Neiva Solange da Silva ${ }^{3}$
}

${ }^{1}$ Doutorando em Educação pela Universidade Estadual Paulista - UNESP, Presidente Prudente, SP. Atualmente trabalha como psicólogo clinico, professor da Fundação educacional de Araçatuba (FEA), professor efetivo de filosofia da Rede Pública de ensino do Estado de São Paulo atuando no Programa de Ensino Integral (PEI). ORCID iD: orcid.org/0000-0002-2544-1289. E-mail: luishenriquezago@hotmail.com

${ }^{2}$ Mestrando em Educação pela Universidade Estadual Paulista - UNESP, Marília, SP. Formado em psicologia pela Faculdade Educacional de Araçatuba, é pós-graduado em psicomotricidade, educação e aprendizagem pela Universidade do Oeste Paulista -UNOESTE, Presidente Prudente, SP, pós graduando em neuropsicologia e graduando em Pedagogia. ORCID iD: orcid.org/0000-0001-6281-2416. E-mail: allandisel@hotmail.com

${ }^{3}$ Mestre em Educação pela Universidade Estadual Paulista - UNESP, Presidente Prudente, SP. Atua como Supervisora de Ensino na Secretaria Municipal de Educação do município de Araçatuba-SP. ORCID: orcid.org/0000-0003-40973598. E-mail: neiva_lee@hotmail.com

\section{RESUMO}

Busca-se com este artigo analisar o conceito de imaginação em sua relação com outras funções da personalidade e alguns aspectos de como ela vem sendo abordada na educação escolar. Os recursos e métodos utilizados para redação do texto envolvem pesquisa bibliográfica de artigos e livros de autores atrelados à teoria histórico-cultural e materialismo histórico-dialético como Vigotski, Leontiev, Marino Filho, Heller, Marx, etc. A capacidade humana de articular em conjunto diversas ações para produzir algo novo é basilar na organização do sistema psicológico humano. Representar o real em imagens possibilitou o avanço artístico, filosófico e científico ao longo da história. No decorrer do texto desmistificamos a ideia de que a imaginação é algo típico de pessoas geniais, mas sim como algo que está presente em todos os momentos da vida. Concluímos que embora os processos criativos e imaginativos sejam vitais para o desenvolvimento humano e sejam na atualidade intensamente trabalhados na educação escolar, a intencionalidade que perpassa essa educação possui um viés mercadológico e capitalista na busca do desenvolvimento de competências para maximizar a exploração do trabalho. Mesmo que o escopo do trabalho educativo para o desenvolvimento da imaginação seja o de promover o capital, consideramos que não deixa de impactar a personalidade e potencializar as capacidades humanas.

Palavras-chave: Imaginação; Atividade criadora; Teoria histórico-cultural.

\section{IMAGINATION AS A CREATIVE ACTIVITY}

\section{ABSTRACT}

This article seeks to analyze the concept of imagination in relation to other functions of the personality and some aspects of how it has been addressed in school education. The resources and methods used for writing the text involve bibliographic research of articles and books by authors linked to historical-cultural theory and dialectical historical materialism such as Vigotski, Leontiev, Marino Filho, Heller, Marx, etc. The human capacity to jointly articulate several actions to produce something new is to be fundamental in the organization of the human psychological system. Representing the real in images has enabled artistic, philosophical and scientific advancement throughout history. Throughout the text, we demystified the idea that imagination is something typical of genius people, but rather something that is present in all moments of life. We conclude that although the creative processes of the imagination are vital for human development and have been intensively worked on in school education today, the intentionality that permeates this education has a market and capitalist bias in the search for the development of skills to maximize the exploitation of work. Even if the scope of the educational work for the development of the imagination is to promote capital, we consider that it still impacts the personality and enhances human capacities.

Keywords: Imagination; Creative activity; Historical-cultural theory. 


\section{LA IMAGINACIÓN COMO ACTIVIDAD CREATIVA}

\section{RESUMEN}

Este artículo busca analizar el concepto de imaginación en relación con otras funciones de la personalidad y algunos aspectos de cómo se ha abordado en la educación escolar. Los recursos y métodos utilizados para la redacción del texto involucran la búsqueda bibliográfica de artículos y libros de autores vinculados a la teoría histórico-cultural y al materialismo histórico dialéctico como Vigotski, Leontiev, Marino Filho, Heller, Marx, etc. La capacidad humana de articular varias acciones juntas para producir algo nuevo debe ser fundamental en la organización del sistema psicológico humano. Representar lo real en imágenes ha permitido el avance artístico, filosófico y científico a lo largo de la historia. A lo largo del texto desmitificamos la idea de que la imaginación es algo propio de las personas geniales, pero algo que está presente en todos los momentos de la vida. Concluimos que si bien los procesos creativos de la imaginación son vitales para el desarrollo humano y se han trabajado intensamente en la educación escolar en la actualidad, la intencionalidad que permea esta educación tiene un sesgo de mercado y capitalista en la búsqueda del desarrollo de habilidades para maximizar la explotación. de trabajo. Si bien el alcance de la labor educativa para el desarrollo de la imaginación es promover el capital, consideramos que aún impacta en la personalidad y potencia las capacidades humanas.

Palabras clave: Imaginación; Actividad creativa; Teoría histórico-cultural.

\section{INTRODUÇÃO}

Este trabalho teórico discute, baseado em pesquisa bibliográfica, o conceito de imaginação e suas implicações na vida social e desenvolvimento humano.

O presente texto pode ser interessante a todos que estudam a imaginação como unidade complexa componente dos processos psicológicos humanos. Ademais, a discussão de processos que envolvem a imaginação emerge como preponderante para autores que almejam entender o desenvolvimento humano e que pretendem utilizar a filosofia materialista histórico-dialética como referência para suas ações e reflexões.

Neste texto discutiremos a relação entre as atividades criadoras e reprodutoras humanas e a imaginação, a relação entre significação e imaginação, abordaremos o processo de afetação sensível da realidade, as emoções, afetos e sua relação com a atividade imaginativa, analisaremos brevemente algumas estruturas neurológicas que sustentam a imaginação, a relacionaremos com o desenvolvimento social humano e conceituaremos imaginação.

Nossa pretensão é desmistificar a concepção de que a imaginação e a atividade criativa são ações relegadas apenas a "pessoas iluminadas", demonstrando que estas fazem parte do cotidiano e são realizadas por todas as pessoas, mesmo que não seja a percepção do senso comum.

A imaginação e a atividade criadora
A imaginação é uma das ações essenciais à atividade criadora do ser humano. Entendemos como atividade criadora o conjunto articulado sistemicamente de ações humanas com a finalidade de gerar algo novo, que pode ser a representação ideal de algum objeto da realidade objetiva no cérebro, a combinação de representações já existentes na memória para o surgimento de algo até então inexistente, elaboração de pensamentos ${ }^{1}$ atinentes às ideias ou coisas e a construção material de algo previamente elaborado pela imaginação e que é projetado na realidade.

Estamos excluindo do conceito de atividade criadora o acaso e o acidental. $\mathrm{O}$ acaso pode ser criativamente aproveitado e servir de base para a confecção de algo novo, mas o acontecimento fortuito em si não pode ser considerado atividade criativa por não envolver a ação prévia de elaboração imaginativa. Destarte, a atividade criativa implica ações conscientes em uma atividade teleológica de construção de algo novo previamente elaborado. Nesta acepção nos colocamos no mesmo sentido de Marx (2011, p. 327) que afirmava:

Uma aranha executa operações semelhantes às do tecelão, e uma abelha envergonha muitos

\footnotetext{
${ }^{1}$ Cotidianamente as pessoas confundem pensamento e ideia. Neste trabalho entendemos ideia como a representação subjetiva e cerebral de um dado da realidade e pensamento como a avaliação qualitativa dos dados representados pelas ideias.
} 
arquitetos com a estrutura de sua colmeia. Porém, o que desde o início distingue o pior arquiteto da melhor abelha é o fato de que o primeiro tem a colmeia em sua mente antes de construí-la com a cera. No final do processo de trabalho, chega-se a um resultado que já estava presente na representação do trabalhador no início do processo, portanto, um resultado que já existia idealmente. Isso não significa que ele se limite a uma alteração da forma do elemento natural; ele realiza neste último, ao mesmo tempo, seu objetivo, que ele sabe que determina, como lei, o tipo e o modo de sua atividade e ao qual ele tem de subordinar sua vontade.

Considerando que a elaboração imaginativa é uma das ações essenciais à atividade criadora definimos imaginação como a ação humana de combinar idealmente diferentes unidades resultando na construção de uma representação cerebral de algo existente ou não.

Significação e imaginação

Compreendemos que a representação cerebral em qualquer atividade criadora ocorre inseparável da atividade simbólica, sem esta, a imaginação seria impossível. Segundo Marino Filho (2015) símbolo pode ser definido como união de dois ou mais signos que em fusão adquirem uma qualidade nova como representação da realidade concreta.

Nascemos num mundo repleto de significados, estes que são desenvolvidos ao longo de gerações, surgem ao ser humano como representações simbólicas por meio da linguagem que internalizamos no processo de aprendizagem.

Segundo Leontiev (2004) a significação possibilita uma forma de pensar teleológica que envolve a identificação do objeto da necessidade, planejar o caminho, meios, ferramentas e condições para alcança-lo. Leontiev (2004, p. 102) diz o seguinte:
Nossa consciência não reflete uma folha de papel apenas como um objeto branco, retangular, e com certa estrutura. Minha consciência reflete-a como folha de papel. As impressões sensíveis que percebo da folha de papel refratam-se de maneira determinada na minha consciência, porque possuo as significações correspondentes: se não as possuísse a folha de papel não passaria de um objeto retangular, branco, com uma estrutura tal.

Vemos que, não fossem os significados construídos na atividade criadora humana, perceberíamos coisas vazias de significação social. Sem o significado o percebido seria apenas certas regularidades e padrões existentes no meio. A aquisição da linguagem na história da evolução possibilitou aos seres humanos pensar a realidade por meio de signos que a representassem, dando subsídios para o desenvolvimento do pensar separado da realidade concreta e para além das necessidades biológicas.

Marx (2011) escreve que o pior dos arquitetos é muito superior a melhor das abelhas, e que embora esta faça inveja com suas colmeias, está limitada a inscrição em seu código genético que determina biologicamente suas ações. Os seres humanos ao designarem signos e significados que representassem o objeto de sua ação, conseguiram pensar apartados da relação presente com as coisas e ao mesmo tempo criar no decorrer de sua atividade vital.

O significado de um objeto torna possível evocá-lo sem sua presença. Vigotski (2003) afirma que não há necessidade de ir, por exemplo, ao deserto do Saara, para criar imagens acerca deste. Crianças que ainda não possuem domínio do manejo de signos percebem o mundo de um modo diferente, como um todo caótico. Para designar um objeto $\mathrm{x}$ ou $\mathrm{y}$, é preciso conhecer o signo que o representa, isto é, a palavra. Saber nomear as coisas é condição necessária para colocá-las em ordem. A atividade criadora está atrelada ao domínio desse processo. 
Considerando que a imaginação envolve a capacidade de articular diferentes componentes da personalidade para criar algo, defendemos que, quanto mais elaborada a capacidade do sujeito organizar suas ideias e pensar sobre elas, maior será a potência imaginativa.

Até aqui foram destacados os processos cognitivos relacionados à atividade imaginativa, entretanto, defendemos que toda representação criadora encerra em si unidades afetivas e emocionais. Neste sentido, a imaginação, como qualquer outra função psicológica superior, possui concomitantemente uma dimensão cognitiva e outra afetiva/emocional.

Afetação, afeto, emoção e imaginação

No decorrer do processo evolutivo a capacidade humana de gerar imagens foi fundamental à atividade criadora. Essa possibilidade surgiu juntamente com novas estruturas cerebrais que nos habilitaram a perceber e a realizar ações cada vez mais complexas na realidade. Com base em Ilyenkov (2010) percebemos a imaginação não somente como resultado de aspectos cognitivos, mas sim fundidos aos aspectos afetivo/emocionais. Para o autor, a capacidade humana de gerar imagens por meio dos órgãos dos sentidos e da articulação do movimento das afetações sensíveis, é fundamental para a formação do sistema psicológico.

A gênese do sistema psicológico está atrelada ao registro das afetações sensíveis do meio. Com base em Marino Filho (2018) entendemos afetação como a irritação provocada por estímulos captados pelos órgãos dos sentidos. O registro cerebral destas afetações surge para o sujeito como ideias, isto é, imagens de sua relação com o mundo, fundidas a um valor afetivo/emocional. A esse valor chamamos de afeto.

No processo de ontogênese não nos limitamos a internalizar significados criados artificialmente pelo grupo dos homens, mas criamos nossos próprios significados, chamados por Leontiev (1978) de sentido pessoal. O sentido pessoal é resultado da valoração qualitativa de nossa relação com o meio. Vemos que, o registro desse movimento eidético na relação do sujeito com seu meio é valorado por ele na forma de afetos. Para Marino Filho (2018) esse valor afetivo constitui o sentido pessoal.

No decorrer do processo de desenvolvimento, significados sociais e sentidos pessoais se fundem para possibilitar a orientação dos sujeitos. Esses significados sociais e sentidos pessoais possibilitam a execução e controle das ações nas atividades que 0 indivíduo desempenha.

A emoção é segundo Vigotski (2003) outro aspecto essencial da imaginação como atividade criadora, esta se encontra ligada a saturação afetiva de estímulos presentes no meio. Com base em Marino Filho (2018) emoção pode ser entendida como resposta orgânica externa e/ou interna de um indivíduo diante da excitação excessiva dos afetos. As emoções nos impelem a reagir fisiologicamente em circunstâncias afetivamente relevantes.

Evidentemente cognição e emoção não atuam separadas no complexo sistema de orientação, execução e controle da conduta. Em qualquer atividade realizada estas estão presentes em maior ou menor grau, mas fundidas de modo inseparável. Nossa posição consiste em afirmar fundamentados em Vigotski (2003), que os aspectos emocionais da personalidade têm fundamental importância na atividade criadora. Estes podem inclusive potencializar a capacidade do sujeito criar se estiverem ligados à atividade.

No que se refere à atividade criadora, as emoções se configuram como inclinação que orientam o sujeito para a atividade. Vigotski (2003) afirma que o sistema emocional de nossas vivências é para o sujeito, fonte de realidade no processo imaginativo. Nas palavras do autor, temos:

Cabe mencionar aqui, em primeiro lugar, as inclinações que não foram satisfeitas em nossa vida. Elas são as verdadeiras fontes da fantasia e determinam seu segundo princípio de realidade. Essa lei pode ser formulada da seguinte maneira:

independentemente de a causa ser real ou irreal, a emoção ligada a ela sempre é real. Se choro pelo herói imaginário de um romance ou fico com medo do terrível monstro que apareceu em meus sonhos ou me emociono ao conversar em uma fantasia com meu irmão morto há muito tempo," 
em todos esses casos as causas de minhas emoções não existem na realidade, mas meu temor, minha pena, minha compaixão continuam sendo, à margem disso, vivências completamente reais. Consequentemente, a fantasia é real de duas maneiras: por um lado, pelo material que a forma; por outro, pelas emoções ligadas a ela (VIGOTSKI, 2003, p. 153).

No processo de construção imaginativa, um fator importante e que marca o acesso às vivências emocionais do sujeito é a recordação. Esta se relaciona a capacidade humana de resgate dos registros mnemônicos. Vigotski (2003) destaca experimentos que demonstram que nossa memória retém mais frequentemente vivências impregnadas de reações emocionais positivas. Para entender um pouco melhor as possibilidades cerebrais de registro de vivências afetivo/emocionais, discutiremos acerca da plasticidade neurológica.

A plasticidade neurológica

Segundo Vigotski (2003) toda matéria tem como uma de suas principais características a plasticidade, isto é, a propriedade de se transformar sob a ação de diversos agentes. A plasticidade possibilita mudanças na estrutura e disposição das moléculas e a conservação dessas alterações. Na natureza encontramos os mais variados tipos de matéria; ferro, nitrogênio, hidrogênio, oxigênio, cálcio, potássio etc., todos eles cedem às pressões do meio e conservam os vestígios dessa influência, mesmo que em medidas diferentes.

Todo esse processo plástico ocorre de forma semelhante com seres orgânicos; vegetações, animais e seres humanos, mesmo porque são constituídos pelo mesmo tipo de matéria existente na natureza. Em nosso organismo o cérebro é a estrutura que mais sofre alterações e conserva as marcas das mudanças ao longo da história. Entendemos que esta plasticidade neurológica é a base para a representação cerebral.

O cérebro possui enorme plasticidade, ou seja, transforma com facilidade sua estrutura sob a influência das pressões do meio, mantendo a marca destas modificações se as pressões são fortes ou se há uma repetição com suficiente frequência. São essas marcas que deixam registradas na memória as vivências do sujeito possibilitando a representação. Podemos comparar essas marcas registradas pela memória como as marcas dos pneus de um veículo por uma estrada que lembram como as rodas passaram por ele, a estrada conserva as marcas das mudanças que ocorreram devido à pressão das rodas, nos possibilitando criar imagens que representam o objeto que passou por ali (VIGOTSKI, 2003).

O cérebro é um órgão moldado pela experiência, desenvolvendo alterações estruturais em resposta as vivências que possibilitam adaptações a condições mutantes e que se repetem. Por causa disto o cérebro de um recém-nascido é muito diverso daquele encontrado em um adulto. De acordo com Cosenza e Guerra (2011) o cérebro de uma criança dobra seu peso e aumenta de tamanho após um ano de vida, para os autores esse crescimento se deve em grande parte as novas ligações neuronais, mas também ao aumento da mielina e de células da glia. Esse grande desenvolvimento cerebral da criança far-se-á por meio de interações com o meio, novas vivências estimulam a formação de novas sinapses no interior do cérebro e no restante do sistema nervoso, ao mesmo tempo em que as vias vão se tornando mielinizadas.

Cosenza e Guerra (2011) afirmam que a plasticidade cerebral está presente mesmo na velhice, isto quer dizer que o sistema nervoso se modifica e conserva as marcas da mudança ao longo de toda a vida, entretanto, pelo menos dois momentos são muitos importantes nesse processo de desenvolvimento; logo após o nascimento e na adolescência.

No desenvolvimento do cérebro são formados neurônios além do necessário para seu funcionamento. Ao nascer, o organismo ajusta a quantidade necessária para execução das atividades neuronais. Nesse processo, muitas células são descartadas pelos mais diversos motivos; porque não conseguiram fazer conexões necessárias, as ligações não eram corretas ou não se tornaram funcionais. Já na adolescência, Consenza e Guerra (2011) escrevem que há um rearranjo em diversas regiões do córtex cerebral por meio da eliminação de diversas sinapses e do aumento na mielinização das fibras nervosas e circuitos neuronais. Segundo os autores essas transformações aumentam a capacidade de 
elaboração do que já foi aprendido e preparam o adolescente para a vida adulta.

A configuração neurológica presente no adulto também se relaciona as vivências e interações deste no meio. O cérebro de um violinista, por exemplo, terá certamente uma expansão da área de córtex na região relacionada ao movimento dos dedos maior do que a de um não violinista por apresentar maior estimulação.

A plasticidade neurológica significa que a cada nova experiência do indivíduo redes de neurônios são rearranjadas e sinapses são reforçadas possibilitando múltiplas respostas ao meio e o registro destas na forma de memórias.

Reis, Petersson e Faísca (2009) ao escreverem sobre a neuroplasticidade e os efeitos da aprendizagem no cérebro citam experimentos que comparam as diferenças neuroanatómicas de substância branca e substância cinzenta entre sujeitos que aprenderam e praticaram a leitura e escrita e outros que por algum motivo sócio-histórico não tiveram essa oportunidade. Os experimentos que se fundamentaram em técnicas morfométricas baseada em volumes revelaram a presença consistente de diferenças na cognição e anatomia cerebral estrutural e funcional. Nas palavras dos autores:

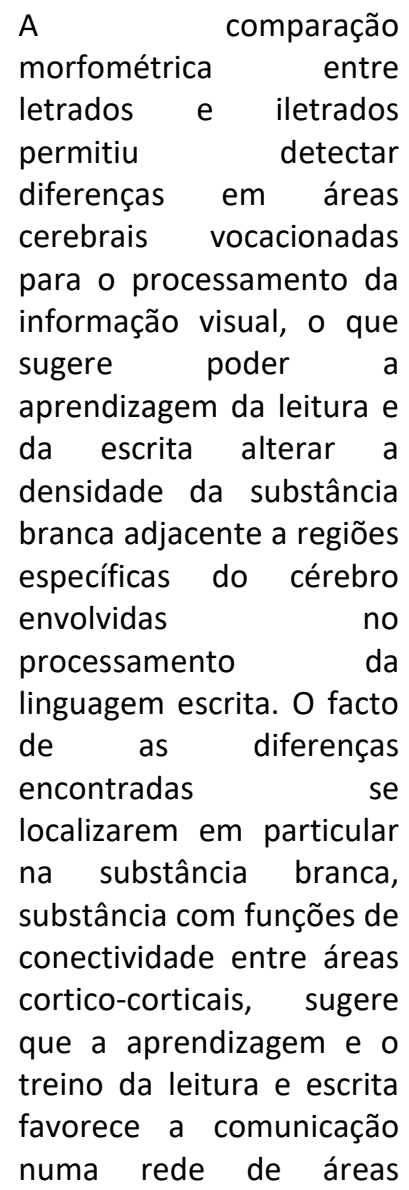

$$
\begin{aligned}
& \text { cerebrais envolvidas } \\
& \text { nestas atividades, } \\
& \text { aumentando a sua } \\
& \text { densidade (REIS; } \\
& \text { PETERSSON; FAÍSCA, 2009, } \\
& \text { p. 12). }
\end{aligned}
$$

Estes dados fornecem evidências de que as vivências do sujeito e atividades que desenvolve ao longo da vida, seja aprender a ler e escrever, tocar violino etc., produzem mudanças significativas na forma da organização cerebral, reforçando a proposição que considera o desenvolvimento humano como o resultado de interações dialéticas entre o indivíduo e o meio.

Defendemos que todo o processo de neuroplasticidade, que propicia o registro e a conservação de informações na forma de memórias possibilita aos seres humanos realizar atividades reprodutoras e criativas.

A atividade reprodutora e sua importância

$$
\text { Vigotski identifica dois tipos }
$$

fundamentais de atividades humanas: uma criadora e uma reprodutora da realidade.

A atividade humana reprodutora da realidade tem como seu substrato a memória. Ela consiste na concatenação e execução de ações que se pautam em antigas impressões gravadas no cérebro.

Nesta categoria de atividades pode ser incluída a repetição de normas de conduta, criadas e elaboradas previamente, a elaboração de uma obra de arte que tenta reproduzir a realidade seja na forma de um desenho, pintura, escultura, música, dança, literatura etc. ou mesmo a tentativa de traduzir o real em uma linguagem científica, seja por meio de uma equação matemática ou outra descrição que utilize a ciência como referência. A atividade nesta categoria não exige a criação de algo novo, apenas a reprodução com maior ou menor exatidão do existente na objetividade ou subjetividade humana.

A capacidade de reproduzir a realidade é essencial às atividades humanas uma vez que é ela que permite o processo de planejamento. Consideramos que o planejamento de uma ação pressupõe a reprodução cognitiva ou material do meio em que ela ocorrerá, para que, com base nesta, o sujeito possa refletir sobre as escolhas possíveis.

A atividade reprodutora também possibilita a constituição de padrões de comportamentos que são acionados em 
situações semelhantes àquelas registradas na memória. Neste sentido ela contribui para a formação de hábitos.

A base dos conceitos e leis científicas radica no afastamento dos elementos acidentais e na preservação do constante no universo de um grupo de entes singulares. Desde Tales de Mileto a ciência busca o que se repete para com base em induções construir afirmações universais que permitam deduções preditivas. Isso não seria possível se os humanos não possuíssem uma capacidade tão boa de memorização e reprodução do real.

Com base nas memórias acumuladas ao longo da nossa existência podemos organizar nossa vida cotidiana.

A cotidianidade e atividade reprodutora

Comumente engendramos um "guardachuva" de normas e convenções, tanto sociais quanto pessoais, que cobrem um segmento de nossa existência estabelecendo procedimentos e rotinas. Esta organização possibilita a estabilidade necessária ao fluir da vida uma vez que oportuniza segurança e velocidade as ações em acontecimentos cotidianos. Não precisar inventar um protocolo novo a cada situação que emerge e saber o que fazer quando algo acontece é indubitavelmente confortante.

$\mathrm{Na}$ maior parte de nossa existência vivemos imersos na cotidianidade, que se caracteriza por um apresentar momentâneo dos efeitos, por ser dotada de motivações efêmeras, por ter um ritmo repetitivo e rígido. Entendemos a vida cotidiana da mesma forma que Heller (1978, p. 17), que afirma:

A vida cotidiana é a vida de todo homem. Todos a vivem, sem nenhuma exceção, qualquer que seja seu posto na divisão do trabalho intelectual e físico. Ninguém consegue identificar-se com sua atividade humanogenérica a ponto de poder desligar-se inteiramente da cotidianidade. E, ao contrário, não há nenhum homem, por mais insubstancial que seja, que viva tão-somente na cotidianidade, embora essa o absorva preponderantemente.
Segundo Heller (1978) uma das características mais marcantes da cotidianidade é o agir pautado por automatismo. As diversas atividades rotineiras, necessárias à produção e reprodução da vida individual, envolvem as pessoas de tal forma que tornam inviável uma ação reflexiva, crítica e aprofundada, ou seja, o pensamento não se eleva ao nível da teoria, do conceito das coisas, abrindo espaço para o automatismo, que encontra suas bases na atividade reprodutora.

A atividade reprodutora dos elementos cotidianos inicia-se com o nascimento e envolve o registro na memória dos sujeitos das condições históricas e sociais. Ao nascermos, nos encontramos em uma cotidianidade específica, que traz em si esquemas já elaborados por outros, o amadurecimento implica a aquisição das habilidades imprescindíveis à vida cotidiana da sociedade em que se está inserido "É adulto quem é capaz de viver por si mesmo a sua cotidianidade" dirá Heller (1978, p. 18). Sobre isso escreve Rossler (2004, p. 1):

[...] a vida cotidiana é
parte inerente à existência
de todo e qualquer
indivíduo. Nessa esfera do
ser social, o indivíduo
apropria-se da linguagem,
dos objetos es
instrumentos culturais,
bem como dos usos e
costumes der sua
sociedader Sem a
apropriação dessas
objetivações reria
impossível a sua existência
e convivência em qualquer
sociedaderamana,
independentemente do
nível de desenvolvimento
dessa mesma sociedade.

Como o psiquismo humano se estrutura por meio do registro na memória, prioritariamente ocorrida no cotidiano, do que foi elaborado pelo gênero humano ao longo da história, podemos afirmar que este psiquismo acaba por reproduzir alguns dos elementos da cotidianidade, ou seja, em correspondência à estrutura material da vida cotidiana existiria uma estrutura correlata subjetiva ${ }^{2}$.

\footnotetext{
${ }^{2}$ Rossler (2004, p. 2) chega a falar em um funcionamento psíquico cotidiano. "Poderíamos falar, então, em um modo de funcionamento psíquico cotidiano, que envolveria formas típicas de perceber o mundo, raciocinar, sentir, comportar-se etc. Em suma,
} 
As representações que emergem da existência cotidiana são profundamente empíricas e preconceituosas, estando umbilicalmente ligadas ao agir. Como os indivíduos não possuem condições de examinar acuradamente as diversas situações de sua atividade cotidiana, acabam por situá-las sob uma perspectiva mais geral, considerando as situações particulares de sua existência a partir de suas experiências anteriores ou de estereótipos já presentes na sociedade. Amiúde, o que é natural e necessário, assumimos esquemas elaborados por outros, que são impingidos pelas escolas, pela televisão, por familiares, chefes no ambiente de trabalho etc. e apenas reproduzimos o já convencionado.

Com base em conteúdos reproduzidos por meio de memórias gravadas no cérebro o indivíduo pode avançar na direção de atividades criativas.

A atividade criativa e a imaginação

Ainda que a atividade reprodutora seja necessária ao fluir da vida e que possibilite segurança e estabilidade, há momentos em que ela não é suficiente para orientar as ações humanas. Ademais, se todas as nossas ações fossem limitadas apenas a reprodução não haveria progresso algum, jamais nos adaptaríamos a situações novas ou planejaríamos o futuro. Segundo Vigotski (2009, p. 4):

Se a atividade do homem fosse limitada a reproduzir o passado, ele seria um ser voltado exclusivamente para ontem e incapaz de se adaptar aos diferentes amanhãs. É precisamente a atividade criativa do homem que faz dele um ser projetado para 0 futuro, um ser que contribui para criar e que modifica seu presente.

Baseando-se em informações memorizadas combinamos elementos já conhecidos para formular imagens de um passado que não vivemos, organizar o presente em uma nova configuração e planejar como desejamos o futuro.

A atividade criadora do cérebro humano de combinar informações para produzir imagens que respaldarão as ações está diretamente ligada a imaginação. Neste sentido tudo o que nos cerca e é resultado da atividade cultural humana é produto da imaginação ou criação que tem como ponto de partida a imaginação. Segundo Vigotski (2009 p. 5): “Todos os objetos da vida diaria, sem excluir os mais simples e habituais, vem a ser algo assim como a imaginação cristalizada." Destarte, a imaginação faz parte do cotidiano de todas as pessoas e não apenas dos gênios criativos.

A atividade cultural criadora dos humanos está intimamente conexionada ao trabalho. Para Marx (2011) o trabalho emerge como elemento essencial do ser humano. Entendemos por essência aqueles elementos que por sua primazia garantam a existência de outros que sem aqueles não existiriam. $O$ trabalho é essencial na medida em que medeia a relação entre o homem e a natureza tornando possível o processo de "emergir" do humano do mundo natural, o que leva a constituição de uma "segunda natureza". Os fenômenos culturais, decorrentes da essência, apresentam-se como uma das muitas formas de ser da essência. Segundo Ranieri (2002,2003, p. 11):

[os fenômenos] agem socialmente no sentido de estabelecer direções possíveis à articulação da essência, constituindo-a, e mesmo determinando a direção tomada pelo complexo como um todo, na medida em que constituem formas que têm por trás a possibilidade da reflexão e da decisão, uma vez que são conscientizadoras da ação humana. Os complexos são capazes de modificar a direção dos caminhos percorridos pela essência, e sua articulação com a primeira das categorias (o trabalho) é a verdadeira natureza movente e movida do processo de estruturação daquela essência. A essência do ser social é, portanto, todo o processo passado do qual ela mesma é o resultado. 
É justamente o processo passado gravado na memória que é o substrato da imaginação criativa. Baseando-se em memórias combinamos e relacionamos diferentes elementos que na realidade não estão conjugados, construímos imagens interpretativas de fenômenos e antevemos acontecimentos futuros.

A imensa capacidade humana de combinar ação e imaginação resultou na atividade de trabalho, por meio do qual a natureza é humanizada. Foi justamente a atividade criativa de trabalho que possibilitou 0 avanço tecnológico e social que vislumbramos na atualidade. Neste sentido, todo o nosso mundo tem o toque da ação imaginativa.

Assim, quanto mais incentivada, estimulada e ensinada for a atividade criativa de combinar imagens e de materializá-las por meio do trabalho maiores serão as condições da humanidade de avançar socialmente.

Propugnamos que a capacidade criativa humana não é inata, isto maximiza a importância das escolas em transmitir experiências que poderão ser combinadas nas ações de adaptação e transformação do real.

A imaginação e as escolas no sistema do capital atual.

Praticamente durante todo o século $X X$ as

escolas ocuparam $O$ papel de meras transmissoras de informações, muitas das quais sem sentido e nexo com a vida dos seus estudantes, a comunidade em que estavam inseridas e seus profissionais.

Este tipo de educação, que Paulo Freire (1998) denominou "bancária", era convergente com a sociedade que Mandel (1985) identificou como Industrial. Nas sociedades organizadas nestes moldes a maior parte das pessoas eram educadas para serem reprodutoras de pensamentos e comportamentos estabelecidos por elites pensantes distantes da realidade e práticas escolares. Destarte, as escolas refletiam os modelos tayloristas/fordistas das indústrias, conformando os estudantes, desde jovens, a alienação e estranhamento. Nestes espaços imaginação e criatividade eram pouco consideradas.

Marx e Engels (2005) ao discutirem a existência do trabalhador neste modo de vida, afirmam que em sua atividade de trabalho esses não se reconheciam e não encontravam prazer, mas apenas sofrimento e fadiga. Ainda que o trabalho seja atividade humana e humanizadora por excelência, uma vez que é por meio dele que se constrói o mundo humano e os homens e mulheres neste, nas sociedades industriais ele se configura como desumanizador, ao ponto de os trabalhadores sentirem-se livres e pessoas de fato apenas fora do trabalho. O trabalho era encarado somente como meio de subsistência que o trabalhador deseja encerrar para ter existência e vida de fato.

Todos os que já presenciaram os minutos que antecedem o sinal de saída das escolas, são conscientes de que elas efetivamente traduzem na vida dos seus estudantes o mundo do trabalho nas sociedades industriais.

Se considerarmos humanização como atividade que leva ao desenvolvimento das características genuinamente humanas, como o pensamento teórico, os sentimentos, a capacidade ética etc. estas escolas são evidentemente pouco humanizadoras e mobilizadoras.

A função psicológica mais utilizada pelos estudantes nestas escolas era a memória, bastava que fossem memorizadas informações que seriam depois reproduzidas ipsis litteris no momento das avaliações que eram quase que exclusivamente somatórias.

Nestes moldes as escolas serviam aos interesses dos capitalistas, uma vez que preparavam a necessária mão-de-obra para as engrenagens do sistema. Mormente, porque a demanda requisitada não era a de pessoas críticas e criativas, mas apenas de "peões" para obedecer e se conformar ao ritmo imposto pela produção.

O advento da inserção da tecnologia digital e da internet nos meios de produção promoveu percuciente transformação no sistema do capital. Ainda que seus objetivos se mantenham, o modus operandi da exploração se reconfigurou em novas exigências a mão-deobra ${ }^{3}$. Temos assim uma ruptura dentro de uma continuidade plena, rompe-se o modo de trabalho, mas mantém-se a exploração do trabalhador em função da lucratividade e acúmulo de capital.

Com o avanço tecnológico nos meios de produção as ações mecânicas realizadas pelos trabalhadores tendem a ser substituídas pelo trabalho das máquinas, tal como já previra Marx e Engels (2005). Como corolário emerge como necessidade a exploração não mais das forças

\footnotetext{
${ }^{3}$ Para informações mais detalhadas sobre o impacto das mudanças tecnológicas na vida dos trabalhadores sugere-se a leitura de Zago (ZAGO, 2019), onde o autor discute esta temática.
} 
físicas do trabalhador, mas das características especificamente humanas, como a criatividade, a inteligência, a socioemotividade entre outras.

Com as forças produtivas se organizando para realização de trabalhos em equipe, para a proatividade e a horizontalização das ações de comando, entre outras mudanças, as escolas passaram a ser premidas a novas formas de estruturação mais adequadas aos novos tempos na produção. Discursos exigindo atividades escolares que incorporem metodologias ativas, ensino norteado por projetos, desenvolvimento e acolhimento das emoções passaram a ser frequentes. Neste contexto a criatividade e a imaginação emergem com preponderância renovada, ainda que direcionada para objetivos muito específicos.

A reprodução das técnicas e metodologias utilizadas pelo setor industrial e que convergem com o modo de ser compatível com as novas formas de trabalho se tornaram Leitmotiv das formações destinadas aos docentes e gestores, muitas vezes sem o devido cuidado de adaptação a realidade escolar. Metodologias como "ciclo PDCA", prática original da montadora de automóveis Toyota, é um exemplo dentre muitos que são frequentes na educação.

A exigência que se impõe é a de uma escola de ensino integral, que conjugue mente e corpo, razão e emoção, integradas no sentido da maximização da lucratividade. Humaniza-se para que se possa explorar o humano.

O manejo das emoções é uma novidade deste modo de organização. Herdeira de uma tradição iluminista que definia os homens como seres racionais, as escolas sempre relegaram o desenvolvimento emocional a penumbra. Considerando o ensino como o ato de produzir direta e intencionalmente, em cada estudante, a humanidade que é produzida coletivamente, tal como defini Saviani (2019), temos que afirmar que não houve durante a maior parte da história das escolas ensino das emoções.

Agora elas passam a ser valorizadas e imensamente consideradas. Ainda que possamos questionar o modo como são trabalhadas não podemos negar a sua presença nos discursos e práticas que envolvem as escolas.

Neste contexto a prática dos profissionais das escolas é ressignificada e redirecionada para a de mediador de conflitos, incentivador, educador etc. As ações desenvolvidas por eles devem se incorporar a atividades que se direcionem para a humanização das relações no interior das escolas.

A cobrança é para que os profissionais das escolas sejam aqueles que sentem a realidade, identificam as necessidades e organizam ações para a obtenção dos resultados que supram as demandas identificadas e requisitadas.

Atento às fragilidades de todo o processo eles devem desempenhar o papel de coordenador para que as ações na escola não sejam desmotivadoras no caminhar. Consideramos que as ações só são motivadoras se percebidas no sentido dos objetivos e se adequadas as condições de execução daqueles que se envolvem na atividade. Assim, é sua função caucionar que as ações propostas e realizadas estejam na direção correta e prover as condições materiais, emocionais, cognitivas para o seu fluir.

Em síntese, os profissionais devem avaliar as situações em que a escola se encontra, considerar toda a heteronomia que estas impõem ao trabalho e a vida, para fundamentado no sólido conhecimento das condições da comunidade escolar traçar planos diretivos no sentido da obtenção dos resultados.

Os resultados devem ser um estudante mais criativo, imaginativo e flexível. A contradição neste processo é o fato de que a criatividade é tolhida em um rígido sentido. As pessoas têm que ser criativas para maximizar a exploração e a lucratividade do sistema do capital. Neste sentido busca-se uma criatividade que potencializa a destruição.

Considerações finais

A imaginação é uma das unidades base da organização do sistema psicológico humano. É justamente a imensa capacidade humana de representar com qualidade o real em imagens que possibilitou o avanço artístico, filosófico e científico desenvolvidos ao longo da história.

Mesmo que a imaginação apareça ao senso comum como algo típico de grandes gênios ela está presente em todos os momentos de nossa existência, a todo instante estamos criando imagens para com base nelas pensarmos a realidade derredor, o passado e o futuro.

Consideramos que a capacidade humana de prever acontecimentos por meio da construção de imagens é um dos elementos que tornou possível a sobrevivência dos humanos como espécie. E a criação da ciência, que entre 
outras coisas, combina a descoberta de padrões e regularidades para com base nisto empreender previsões atinentes ao futuro.

A capacidade imaginativa humana é tão importante que pode ser apontada até mesmo como causa de transtornos psicológicos como a ansiedade, que está muito relacionada ao sofrimento decorrente do medo por algo que possa vir a acontecer. A pessoa imagina situações que disparam respostas orgânicas relacionadas a pânico e situações de perigo.

Nos últimos anos a imaginação e a criatividade vem sendo intensamente trabalhadas nas escolas. Há uma busca para que os estudantes desenvolvam a capacidade imaginativa. A intencionalidade que perpassa essa busca envolve o interesse dos capitalistas em maximizar a exploração do trabalho. Marx (2011) lembra que em os capitalistas em alguns momentos se comportam como bravas toupeiras, que cavam os buracos onde se enterraram. 0 desenvolvimento da imaginação, ainda que com o escopo de promover o capital, não deixe de impactar a personalidade e potencializar as capacidades humanas.

Estudar a imaginação e suas relações com a atividade reprodutora e criativa humana é de suma importância para o entendimento da sociedade em que vivemos e das pessoas em particular.

Longe de esgotar essa discussão buscamos contribuir com a percepção de que a atividade imaginativa é algo presente em nosso cotidiano, mesmo que não notemos esta verdade.

\section{REFERÊNCIAS}

COSENZA, R. M.; GUERRA, L. B.. Neurociência e educação: como o cérebro aprende. Porto Alegre: Artmed, 2011.

FREIRE, P. Pedagogia do oprimido. 25. ed. Rio de Janeiro: Paz e Terra, 1998.

HELLER, Á. O Cotidiano e a história. Rio de Janeiro: Hucitec, 1978.

ILYENKOV, Evald. Psychology Journal of Russian and East European Psychology, v. 4, n. 48, p. 949, 2010.

LEONTIEV, A. N.. Actividad, conciencia y personalidad. Buenos Aires: Ediciones del Hombre, 1978.
LEONTIEV, A. N. O desenvolvimento do Psiquismo. 2. ed. São Paulo: Centauro, 2004.

MANDEL, E. O capitalismo tardio. São Paulo: Nova Cultural, 1985.

MARINO FILHO, A. Dos cuidados à pessoa no processo terapêutico: afetividade e relações de poder na superação do sofrimento psicológico. In: CONGRESO INTERNACIONAL, 8. ; NACIONAL DE PSICOLOGÍA CLÍNICA, 13., 2015, Granada, ES. Anais [...]. Granada, ES: AEPC, 2015. Disponível em:

http://www.aepc.es/psclinica_web/LIBRORESUM ENES_2015.pdf. Acesso em: $10 \mathrm{dez} .2015$.

MARINO FILHO, A. Sofrimento Psicológico no Processo Educativo. In: JORNADA DO NÚCLEO DE ENSINO. 17.; CONGRESSO INTERNACIONAL SOBRE A TEORIA HISTÓRICO-CULTURAL SIGNIFICADO E SENTIDO NA EDUCAÇÃO PARA A HUMANIZAÇÃO. 4., 2018, Marília. Anais [...]. Marília: Unesp, 2018.

MARX, K.;ENGELS, F. Manifesto comunista. São Paulo: Boitempo, 2005.

MARX, K. O 18 de Brumário de Luís Bonaparte. São Paulo: Boitempo, 2011.

MARX, K. O capital: Crítica da economia política. 2. ed. São Paulo: Boitempo, 2011.

RANIERI, J. Sobre o conceito de ideologia. Estudos de Sociologia, Araraquara, v. 13/14, p. 736, 2002,2003.

REIS, A. I. D.; PETERSSON, K. M.; FAÍSCA, L. (2009). Neuroplasticidade: Os efeitos de aprendizagens específicas no cérebro humano. In: NUNES, C.; JESUS, S. (ed.). Temas actuais em Psicologia (). Faro: Universidade do Algarve, 2009.p. 11 - 26

ROSSLER, J. H. O desenvolvimento do psiquismo na vida cotidiana: aproximações entre a psicologia de Aléxis Leontiev e a teoria da vida cotidiana de Agnes Heller. Cad. Cedes. Campinas, v. $24,{ }^{\circ} 62$ p. 100-116, abr. 2004. https://doi.org/10.1590/S0101$\underline{32622004000100007}$ 
SAVIANI, D. A pedagogia histórico crítica, quadragésimo ano: novas aproximações. Campinas: Autores Associados, 2019.

VIGOSTKI, L. S.. Psicologia Pedagógica. Trad. Claudia Schilling. Porto Alegre: Artmed, 2003a.

VIGOSTKI, L. S. La Imaginación y el arte en la infancia: ensayo psicológico. Madrid: Akal, 2003b.

VIGOTSKI, L. S. A construção do pensamento e da linguagem. 2. ed. São Paulo: Martins Fontes, 2009.

ZAGO, L. H. O trabalho como categoria ontológica: uma análise a partir da obra cinematográfica? Eu, Daniel Blake. Colloquium Humanarum, v. 16, n. 4, p. 18-38, 2019. https://doi.org/10.1590/S0101$\underline{32622004000100007}$ 